\title{
Idiopathic intracranial hypertension
}

\author{
Michel J. Belliveau MD, Martin W. ten Hove MD MEng
}

\section{Idiopathic intracranial hypertension primarily affects young obese women}

More than $93 \%$ of people with idiopathic intracranial hypertension (previously called pseudotumour cerebri and benign intracranial hypertension) are obese. The annual incidence of the disease is highest among young obese women, at an estimated 20 per $100000 .{ }^{1}$ The median age at onset is 34 years. ${ }^{1} \mathrm{~A}$ higher body mass index and a higher percentage of weight gain in the past year are associated with increased risk. ${ }^{2}$ Medications can also cause elevated intracranial pressure (see point 5).

\section{Magnetic resonance venography can rule out important alternate diagnoses}

In addition to ruling out structural causes of increased intracranial pressure, most importantly neoplasms, magnetic resonance yenography can rule out cerebral venous sinus thrombosis, which is the main differential diagnosis in young women, particularly those taking oral contraceptives. ${ }^{5}$

\section{Management strategies lack robust evidence, but weight loss is the cornerstone}

Management strategies have gained acceptance based on clinical success over many years, but large prospective trials are lacking. ${ }^{6}$ A strategy of weight loss, restricted sodium intake and acetazolamide (250 mg four times daily) has become common practice. For progressive vision loss, insertion of a cerebrospinal fluid shunt, and in some centres fenestration of the optic nerve sheath, may be offered. ${ }^{6}$

\section{Diagnosis is based on clinical features, an intracranial pressure greater than $250 \mathrm{~mm} \mathrm{H}_{2} \mathrm{O}$ and no culprit lesion on neuroimaging}

Daily headaches, which may be incapacitating, and reduced vision are the hallmark symptoms. (The diagnostic criteria for idiopathic intracranial hypertension are listed in Appendix 1, at www .cmaj.ca/lookup/suppl/doi:10.1503 /cmaj.110072/-/DC1.) The vision changes are secondary to swelling of the optic nerve due to raised intracranial pressure (papilledema) (Figure 1), which is evident clinically in up to $95 \%$ of patients with idiopathic intracranial hypertension. ${ }^{3}$ Transient visual obscuration - vision loss or "dimming" lasting seconds — is the most common visual symptom. Visual acuity is often impaired less than visual field in these patients. Horizontal diplopia from abducens nerve paresis may also occur. Pulsatile tinnitus, present in $60 \%$ of patients, was shown to be the most specific symptom in a large case-control study. ${ }^{4}$

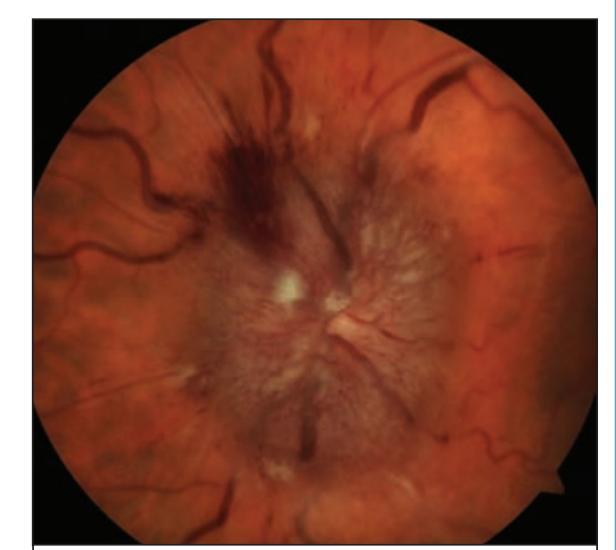

Figure 1: Papilledema in a young obese woman with idiopathic intracranial hypertension. The degree of papilledema does not correlate with the intracranial pressure or the degree of visual dysfunction.
Medications associated with increased intracranial pressure should be stopped

Tetracycline and related compounds, vitamin $\mathrm{A}$ and analogs, steroids and lithium are among the agents that have been associated with increased intracranial pressure. ${ }^{5}$

\section{References}

1. Glueck CJ, Aregawi D, Goldenberg N, et al. Idiopathic intracranial hypertension, polycystic-ovary syndrome, and thrombophilia. J Lab Clin Med 2005; $145: 72-82$

2. Daniels AB, Liu GT, Volpe NJ, et al. Profiles of obesity, weight gain, and quality of life in idiopathic intracranial hypertension (pseudotumor cerebri). Am J Ophthalmol 2007;143:635-41.
3. Digre KB, Nakamoto BK, Warner JE, et al. A comparison of idiopathic intracranial hypertension with and without papilledema. Headache 2009; 49: 185-93.

4. Giuseffi V, Wall M, Siegel PZ, et al. Symptoms and disease associations in idiopathic intracranial hypertension (pseudotumor cerebri): a case-control study. Neurology 1991;41:239-44.

5. Friedman DI, Jacobson DM. Diagnostic criteria for idiopathic intracranial hypertension. Neurology 2002;59:1492-5.

6. Lueck C, McIlwaine G. Interventions for idiopathic intracranial hypertension. Cochrane Database Syst Rev 2005;(3):CD003434.

Competing interests: None declared.

This article has been peer reviewed.

Affiliation: From the Department of

Ophthalmology, Queen's University, Kingston, Ont.

Correspondence to: Dr. Martin ten Hove,

tenhove@queensu.ca

CMAJ 2011. DOI:10.1503/cmaj.110072 